\title{
AVALIAÇÃo de IMPACTOS DE OdORES EM BACIAS HIDROGRÁFICAS COM PRODUÇÕES DE SUÍNOS
}

\section{EVALUATION OF ODOR IMPACTS IN HYDROGRAPHIC BASINS WITH SWINE PRODUCTION}

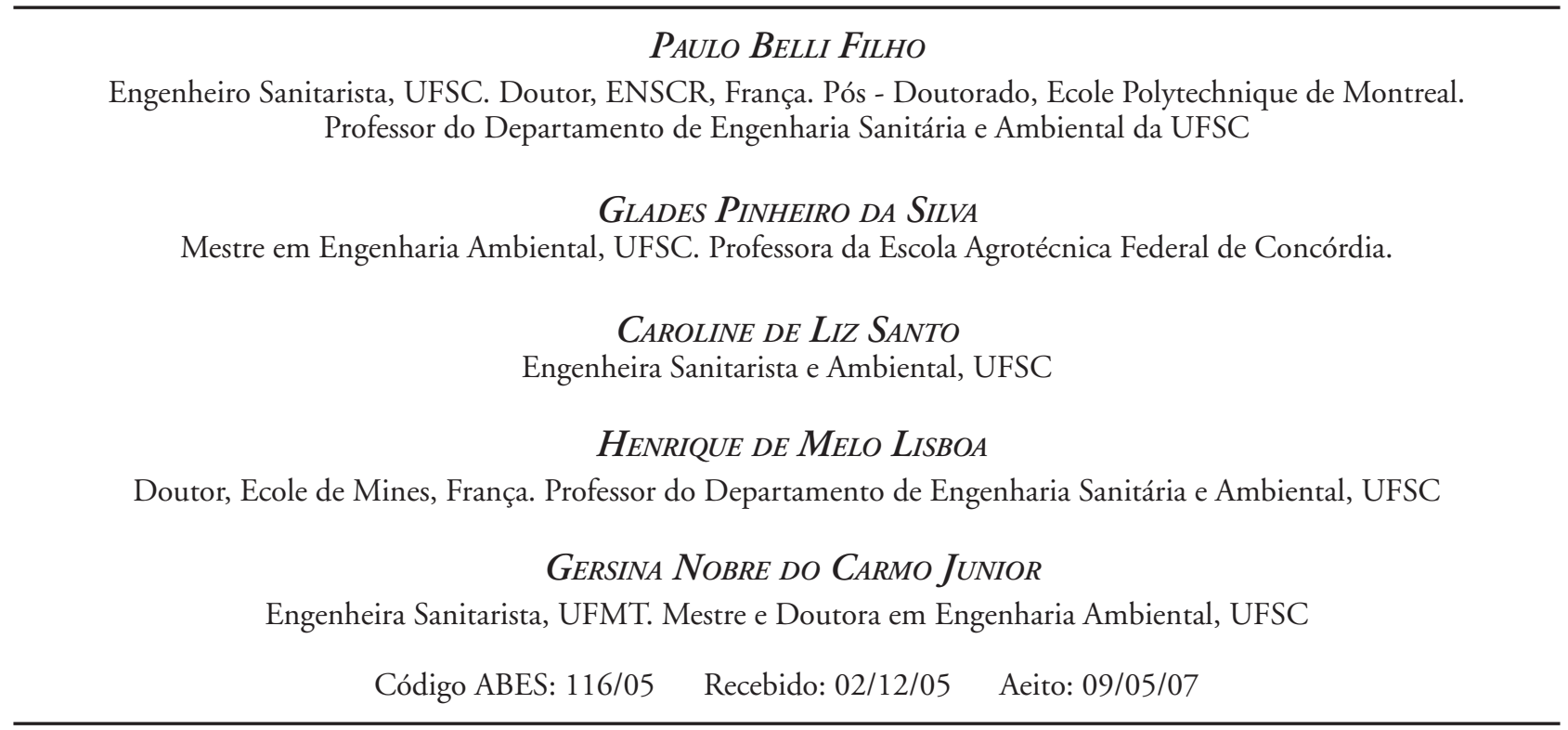

\section{RESUMO}

A bacia hidrográfica de Rio Fragosos, no oeste catarinense e a bacia hidrográfica do Rio Cachoeirinhas, no sul de Santa Catarina foram unidades pilotos para a aplicação de duas metodologias para avaliaçôes de odores provenientes da suinocultura. Na bacia do Rio Fragosos ficou destacado para a grande maioria das pessoas situaçôes de ambiente desagradável, muito desagradável e extremamente desagradável. As concentrações dos odores obtidos na bacia do Rio Cachoeirinhas, determinadas a montante e a jusante de uma propriedade piloto, no interior de uma granja de criação de animais, sobre uma unidade de armazenamento de seus dejetos e na residência de um produtor variaram de $257 \mathrm{UO} / \mathrm{m}^{3}$ à $963 \mathrm{UO} / \mathrm{m}^{3}$. Estas concentraçôes indicaram intensidades de odores com níveis forte a muito forte.

PALAVRAS-CHAVE: Bacia hidrográfica, odores, olfatometria, olfatômetro, suinocultura.

\begin{abstract}
The River Fragosos hydrographic basin in the west of Santa Catarina and the River Cachoeirinhas hydrographic basin in the south of Santa Catarina were the pilot units for the application of two methodologies for the evaluation of odors originating from swine rearing. In From the results obtained for the River Fragosos basin, for the great majority of responses, unpleasant, very unpleasant and extremely unpleasant environmental situations were highlighted. The odor concentrations obtained for the River Cachoeirinhas basin, determined upstream and downstream of a pilot property, inside animal rearing smallholdings, above a waste storage unit and a producer's home, varied from $257 \mathrm{OU} / \mathrm{m}^{3}$ to $963 \mathrm{OU} / \mathrm{m}^{3}$. These concentrations indicate odor intensities with strong and very strong levels.
\end{abstract}

KEYWORDS: Swine, odors, olfactometry, olfactometer, hydrographic basin.

\section{INTRODUÇÃO}

As regióes produtoras de suínos, no sul do Brasil, apresentaram nos últimos anos uma crescente poluição ambiental devido a uma prática insustentável proveniente da falta de planejamento e de políticas adequadas para a suinocultura no país. O Estado de Santa Catarina é o mais dinâmico nesta cadeia produtiva no Brasil, com 5,5 milhões de suínos, possuindo a maior produção no oeste catarinense e tendo um plantel significativo, também, no sul deste estado. Esta atividade polui as águas, o ar, os solos e proporciona conflitos com outras atividades.

A poluição do ar pode estar relacionada a níveis macro regionais, podendo integrar-se na escala global junto às emissões de $\mathrm{CO}_{2}$ e $\mathrm{CH}_{4}$, colaborando com o aquecimento do ambiente terrestre. Em nível micro regional se tem o efeito principal do desconforto ambiental proveniente de insetos e maus odores.

Os odores, de acordo com o tempo de exposição e ligados a fatores do meio ambiente, podem causar náuseas, irritações, estresse, dores de cabeças e outras implicações à saúde ambiental (Belli Fo, 1995; Silva, 2002).

A legislação ambiental de Santa Catarina (FATMA, 1982) determina que os odores de um local de emissão não podem ser percebidos fora de seu 
terreno. No entanto existem fatores que dificultam a aplicação desta lei, haja vista que diversos aspectos estão em jogo e entre eles a aplicação de metodologias adequadas que avaliem e indiquem os riscos ambientais. Vários trabalhos e eventos têm sido realizados para desenvolver e consolidar a olfatometria como instrumento de gestão dos odores para o saneamento ambiental, se destacando VDI/DIN (2004) e ADEME/AFITE (2005). Como resultados, em função dos avanços desta ferramenta, os valores de limites permitidos que alguns países começam a adotar para a concentrações de odores variam entre $3 \mathrm{UO} / \mathrm{m}^{3}$ à $12 \mathrm{UO} / \mathrm{m}^{3}$.

A percepção dos odores possui sua complexidade, pois é uma resposta sensitiva de pessoas quando expostas a eles, que apresentam um comportamento psicofísico em função de aspectos ambientais, de saúde e tipo de emissão entre outros. Estas características estão relacionadas com as condições de exposiçôes das pessoas e dos fatores odorantes de: freqüência, intensidade, concentração, duração, característica hedônica e aspecto psicofísico (Belli Fo \& De Melo Lisboa, 1998; Sheridan et al, 2004). Para explicar o comportamento de um odor e sua resposta psicofísica utiliza-se a lei de Stevens, que representa a intensidade odorante em função da exposição humana a diferentes concentraçōes.

As metodologias de avaliaçôes dos odores (olfatometria) para serem utilizadas como ferramentas de apoio à gestão de impactos de diversas fontes sobre o meio ambiente estão em processo de consolidação. A olfatometria possui como princípio avaliar incômodos, determinar os riscos e os limites de exposição dos odores sobre as pessoas. Os odores podem ser avaliados através de enquetes olfatométricas realizadas junto às comunidades, tendo-se como modelo as recomendaçôes da norma VDI 3883 (1993) para a determinação da percepção humana sobre o seu ambiente.

Para a avaliação da intensidade de um odor existem escalas de referências que representam graus diferentes de incômodos, podendo seguir recomendaçōes normatizadas. Para a avaliação desta variável pode-se trabalhar com pessoas treinadas ou diretamente com cidadãos de um local a ser avaliado.

A determinação da concentração do odor de uma fonte é obtida através do uso de olfatômetro de diluiçãa dinâmica e necessitando de um júri de pessoas preparadas para estas mediçóes. A concentração do odor de uma amostra é expressa em $\mathrm{UO} / \mathrm{m}^{3}$ (unidade de odor/metro cúbico de ar) e uma unidade desta variável representa em relação ao butanol no ar atmosférico $123 \mu \mathrm{g} / \mathrm{m}^{3}$ (Stuetz \& Frechen, 2001).

Outra ferramenta que pode ser aplicada e integrada conjuntamente com as metodologias de avaliação de impactos de odores é o uso de modelos matemáticos, que verificam sua dispersão na atmosfera (De Melo Lisboa, 1996; Rouil, 2005). Estas metodologias podem ser aplicadas em conjunto para as determinaçóes de parâmetros odorantes de um local. Com este conjunto de metodologias e os avanços existentes a olfatometria torna-se uma ferramenta que possibilita a fixação dos limites de exposiçôes dos odores sobre as pessoas, através do emprego de metodologias que utilizam como base de detecção o aparelho olfativo humano. Ela é importante para se implementar uma gestão dos odores integrada ao saneamento ambiental.

Em relação à suinocultura os seus odores são provenientes das instalações de criação dos animais, unidades de armazenamento e de tratamento dos dejetos, aplicações deste produto no solo, transporte dos suínos e emissões de corpo receptor poluído que recebe o lançamento direto ou indireto de despejos suinícolas (Belli $\mathrm{F}^{\circ}$, 1995).

Países produtores de suínos têm dedicado atenção aos incômodos odorantes provenientes desta atividade objetivando a fixação de normas específicas e limites para este fator de desconforto ambiental segundo Joncas et al (2003), Sheridan et al (2004), VDI (2004) e ADEME/AFITE (2005). Por exemplo, na Irlanda foi fixada a concentração de odor de $6 \mathrm{UO} / \mathrm{m}^{3}$ como limite máximo para a suinocultura.

Nesta pesquisa são apresentados os resultados das aplicaçôes de duas metodologias para a determinação do impacto odorante em duas comunidades suinícolas. Em uma microbacia hidrográfica foi utilizado um olfatômetro para determinar as concentrações dos odores e em outra foi realizada uma enquete olfatométrica para determinar a percepção ambiental da comunidade envolvida com a suinocultura.

\section{MATERIAIS E MÉTODOS}

\section{Locais de estudos}

Os trabalhos se desenvolveram nas bacias hidrográficas do Rio $\mathrm{Ca}$ choeirinhas, em Braço do Norte e no Rio Fragosos, em Concórdia, ambas em Santa Catarina no sul do Brasil, possuindo superfícies aproximadas, respectivamente, de $20 \mathrm{~km}^{2}$ e $60 \mathrm{~km}^{2}$. Estas duas bacias foram selecionadas por estarem localizadas no berço da produção de suínos em duas regiōes representativas para esta atividade. $\mathrm{O}$ Rio Cachoeirinhas está localizado na regiāo hidrográfica do Rio Tubarão, tendo sua foz no litoral catarinense, enquanto que o Rio Fragosos está na região hidrográfica do alto Rio Uruguai que se integra a bacia do Rio da Prata. $\mathrm{Na}$ microbacia do Rio Cachoeirinhas existe a predominância da produção de suínos, com 32 propriedades, totalizando aproximadamente 16.000 animais. No Rio Fragosos existem 197 propriedades distribuídas entre a avicultura, bovinocultura e com a atividade $\mathrm{da}$ suinocultura em 127 delas, totalizando uma ordem 40.000 suínos. Estes dados caracterizam estas bacias hidrográficas com elevadas densidades de suínos.

\section{Metodologia aplicada na bacia hidrográfica do Rio Fragosos - determinação da percepção ambiental}

Para a determinação da percepção ambiental da população que reside na região rural da bacia hidrográfica do Rio Fragosos, foi aplicado um questionário, preenchido através de entrevistas, adaptando-se aos modelos propostos na norma VDI 3883 (1993), Perrin et al, (1994) e pela Comissão Internacional de Engenharia Rural (CGIR, 1994).

$\mathrm{Na}$ regiāo foram entrevistados representantes de 102 famílias, tendo 75 relacionados à produção de suínos e 27 não ligados a esta atividade e sem relaçôes com a agropecuária. $\mathrm{O}$ questionário teve como princípio obter informaçôes sobre as origens dos odores na bacia e na propriedade, o grau de desagradabilidade, ponto de vista sobre poluição ambiental, condições climáticas e momentos de percepção dos odores, entre outras questões.

Os odores foram quantificados através da determinação do índice de 
incômodo (I) obtido através da Equação 1. A Tabela 1 identifica as categorias de incômodos com os seus respectivos pesos de influências sobre elas, conforme a norma VDI 3883 (1993).

$\mathrm{I}=\frac{1}{N} \sum_{i=0}^{5} \mathrm{~W}_{\mathrm{i}} \mathrm{N}_{\mathrm{i}}$

Onde :

$\mathrm{N}$ - número total de observadores i - categoria de incômodo odorante $\mathrm{W}_{\mathrm{i}}$ - fator de odor por categoria odorante $\mathrm{i}$

$\mathrm{N}_{\mathrm{i}}$ - número de respostas da categoria $\mathrm{i}$

Para medir o grau de associação entre os níveis de fatores foi aplicado o método de qui-quadrado com nível de significância de 5\%. As hipóteses formuladas foram avaliadas pelo teste da razão de verossimilhança, com grau de associação obtido através do quiquadrado. As análises estatísticas foram processadas no modelo SAS, versão 8.2 (SAS/STAT ®).

\section{Metodologia aplicada na microbacia hidrográfica do Rio Cachoeirinhas - determinação da concentração de odor}

Para se aplicar a metodologia de avaliação dos odores na microbacia hidrográfica do Rio Cachoeirinhas, foram escolhidos seis pontos de amostragens conforme a Figura 1 e Tabela 2. Os pontos 1,2 e 3 estão localizados ao longo do rio principal enquanto os pontos $4,5 \mathrm{e}$ 6 estão no interior de uma propriedade piloto produtora de suínos.

O método usado para as amostragens foi o indireto, através do enchimento de ar odorante em saco tedlar, através de recipiente com vácuo especialmente construído para esta finalidade, conforme esquema da Figura 2. Foram medidas, nos locais, a velocidade do vento e sua direção, umidade do ar e temperatura.
Foi realizada uma campanha de trabalho para as determinações das concentraçôes odorantes utlizando um olfatômetro de diluição dinâmica, com marca Odile-Odotech. Este olfatômetro possui seis postos de respostas para os jurados analisarem, no mesmo instante cada amostra. O aparelho dilui a amostra a ser analisada com ar inodoro a valores em que 50\% dos jurados detectam a sua presença. Esta diluição representa o limite de percepção e é convertido na concentração odorante. Este equipamento fornece os valores das concentraçóes dos odores de acordo com a norma americana ASTM E679/91 e a européia CEN - prEN 13725. Para este trabalho foi constituído um júri olfatométrico de seis pessoas preparadas para tal finalidade seguindo as recomendações destas normas.

\begin{tabular}{ccc} 
Tabela I - Categorias de incômodos (i) e pesos dos fatores dos odores (Wi) \\
\hline Caráter Hedônico & $\mathrm{i}$ & $\mathrm{Wi}$ \\
\hline Sem odor & 0 & 0 \\
Odor sem ofensividade & 1 & 0 \\
Odor pouco ofensivo & 2 & 25 \\
Odor ofensivo & 3 & 50 \\
Odor muito ofensivo & 4 & 75 \\
Odor extremamente ofensivo & 5 & 100 \\
\hline
\end{tabular}

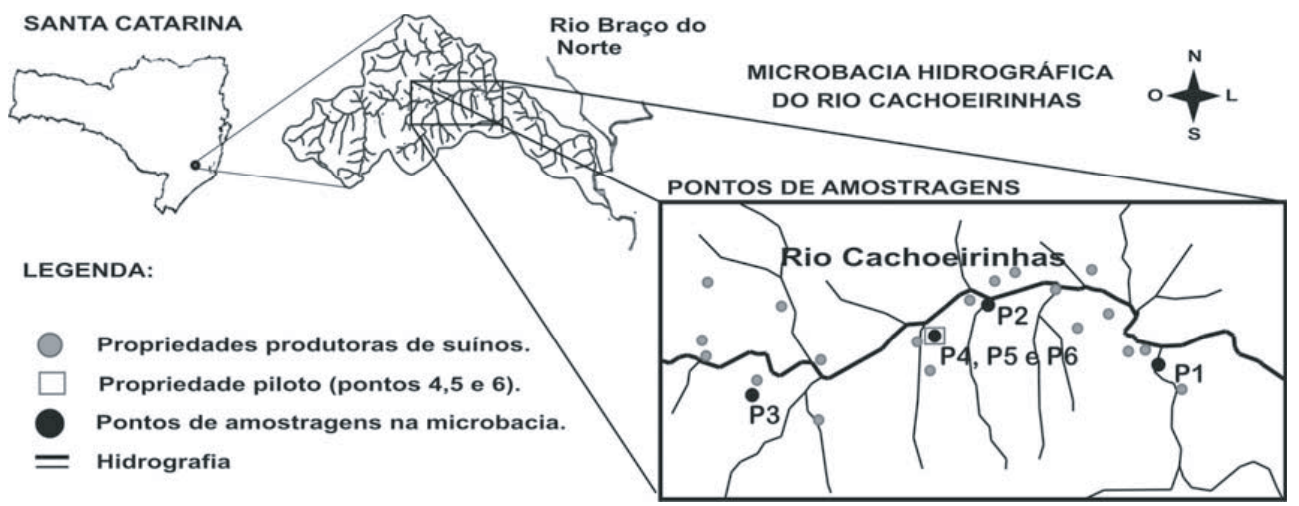

Figura I- Pontos de amostragens na microbacia hidrográfica do Rio Cachoeirinhas

Tabela 2 - Pontos de amostragens dos odores

\begin{tabular}{cc}
\hline Ponto de amostragens & Nome de referência \\
\hline 1 & Jusante da propriedade \\
2 & Campo de futebol \\
3 & Montante da propriedade \\
4 & Interior da granja com suínos \\
5 & Tanque pulmão \\
6 & Residência do produtor \\
\hline
\end{tabular}




\section{RESULTADOS E DISCUSSOES}

\section{Bacia Hidrográfica do Rio Fragosos}

As Figuras 3, 4 e 5 apresentam os resultados desta pesquisa sobre a percepção ambiental dos cidadãos da bacia hidrográfica do Rio Fragosos, em sua região rural, tendo como parâmetro de referência os odores relacionados à suinocultura. Existem três grupos de perguntas sendo que as suas respectivas respostas receberam tratamento dos dados para a determinação da percepção populacional.

No primeiro grupo, Figura 3, estão dispostas questōes referentes aos aspectos de fatores do ambiente sobre os odores: freqüência, espaços de tempos e condições físicas. No segundo grupo se tem as fontes odorantes e no terceiro grupo, os aspectos relacionados à percepção do odor quanto à saúde ambiental dos entrevistados.

Observa-se que existem proximidades de percepções entre os produtores de suínos com os cidadãos não produtores. Além disto, as respostas dos produtores de animais apresentaram informaçōes, que demonstraram confiabilidade na enquete, haja vista que não escamotearam sua real percepção sobre o local em que habitam, sendo sinceros nas respostas fornecidas. Preliminarmente se observa, através de uma análise especializada, que foram obtidas informações coerentes com o ambiente em que vivem.

A percepção dos odores resultantes do primeiro grupo de questôes, conforme a Figura 3, indica a existência de contribuiçõoes diretas destes fatores. A questão sobre a freqüência de percepção foi a que apresentou maior diferença de respostas entre produtores e não produtores. Para os primeiros a sua percepção é diária em sua maioria, enquanto que o segundo grupo de entrevistados apresentou uma percepção esporádica dos odores. Os produtores estão constantemente em seu ambiente de produção de suínos e para eles fica difícil detectar diferentes intensidades dos odores provenientes destas atividades. Para os não produtores, considerando que eles transitam com freqüência fora desta região rural e passam por diferentes ambientes se pode justificar a percepção diferente. Para as outras questôes apresentadas os

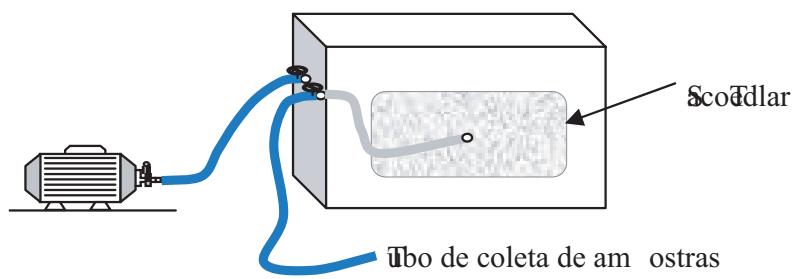

Figura 2 - Sistema de coleta de amostras gasosas

Produtor

Não-produtor
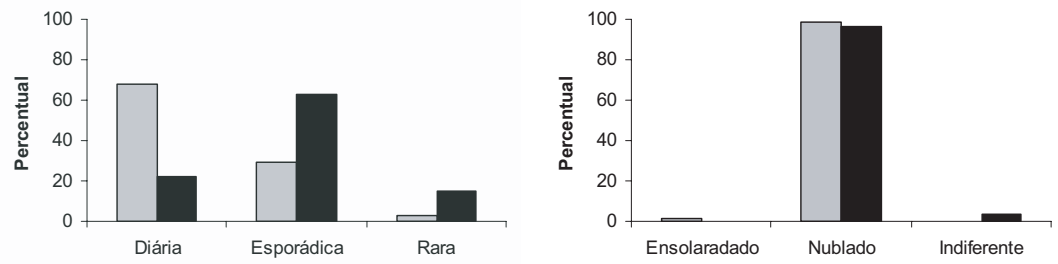

Percepção dos odores no meio rural

Percepção conforme condição meteorológica
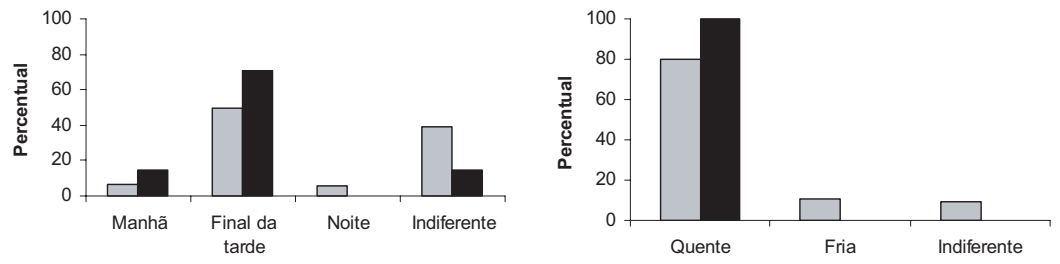

Período de maior percepção de odores

Percepção conforme temperatura ambiente

Figura 3 - Percepção dos odores em função das condições físicas do ambiente

odores são mais percebidos, para ambas as categorias de entrevistados, no final de tarde e sob condições meteorológicas mais favoráveis em dias quentes e em condições nubladas.

A Figura 4 apresenta as fontes responsáveis pelos maus odores presentes nesta atividade e ela mostra que os percentuais de respostas foram iguais para ambas as categorias de entrevistados, em cada situação. A fonte de maior odor na bacia hidrográfica é proveniente do momento de aplicação dos dejetos no solo, conforme essa figura. Em segundo grau de importância, se apresenta o sistema de manejo dos dejetos (armazenamento e tratamento) nas propriedades e em terceiro aqueles originários das instalaçôes de criação dos animais. Estas fontes são as mesmas identificadas através do trabalho de Belli Fo (1995).

A percepção dos odores em relação aos incômodos dos odores e riscos à saúde dos cidadãos da bacia hidrográfica do Rio Fragosos, é apresentada na figura 5. Para os fatores irritação e mal estar, aproximadamente $20 \%$ são percebidos pelos produtores, enquanto que na ordem de $60 \%$ os consideram esporádicos. Para os não produtores, aproximadamente $40 \%$ percebem estes fatores de saúde com freqüência e o igual percentual para a percepção esporádica.

Em relação à característica hedônica, que identifica o grau de agradabilidade, os produtores mostraram em sua maioria, que vivem em um ambiente desagradável, muito desagradável e extremamente desagradável.Os percentuais foram respectivamente, de $28 \%, 26 \%$ e $32 \%$ (figura 5). Para os não produtores, ficou destacado que $60 \%$ dos entrevistados apontaram para um ambiente extremamente desagradável. Foi observada a inexistência de respostas de percepção agradável, justificando a ausência no histograma. Os percentuais são diferentes para cada fator, ficando evidente que a maioria da população entrevistada vive em ambiente desagradável a extremamente desagradável, conforme as suas percepções de ambiente. 
Quanto ao índice de odor (I) para os produtores foi obtido valor de 69 , indicando uma percepção de incômodo ofensivo a muito ofensivo. Para os não produtores foi calculado o índice com valor 81 tendo a percepção de odor considerada muito ofensiva a extremamente ofensiva.

Estes resultados refletem as condiçôes de exposição dos cidadãos que convivem com a produção de suínos e o seu meio, seja como produtor ou morador local sem produzir animais. Observa-se estar o local em conflito com a legislação ambiental, apresentando um ambiente insalubre colocando em risco as condições de saúde ambiental de sua população.

\section{Micro bacia Hidrográfica do Rio Cachoeirinhas}

As condições meteorológicas existentes nos dias de amostragens estão descritas na Tabela 3 e destaca-se que eles estavam com boa intensidade solar. É importante observar que as amostragens nos pontos externos à propriedade piloto não foram realizadas na mesma data daquelas feitas em seu interior. A Tabela 4 mostra as concentrações odorantes obtidas para cada ponto amostrado. Observa-se que existem diferentes valores de concentrações odorantes para a mesma amostra quando se compara com as normas aplicadas. Segundo Carmo Jr. (2005) isto ocorre em função dos respectivos modelos aplicados ao tratamento dos dados obtidos no olfatômetro relacionados à dispersão das respostas dos membros do júri olfatométrico.

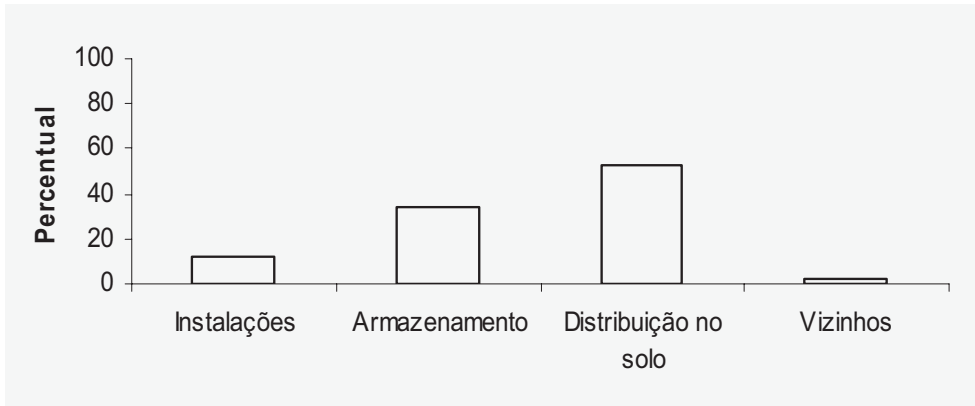

Figura 4 - Fontes de odores na suinocultura

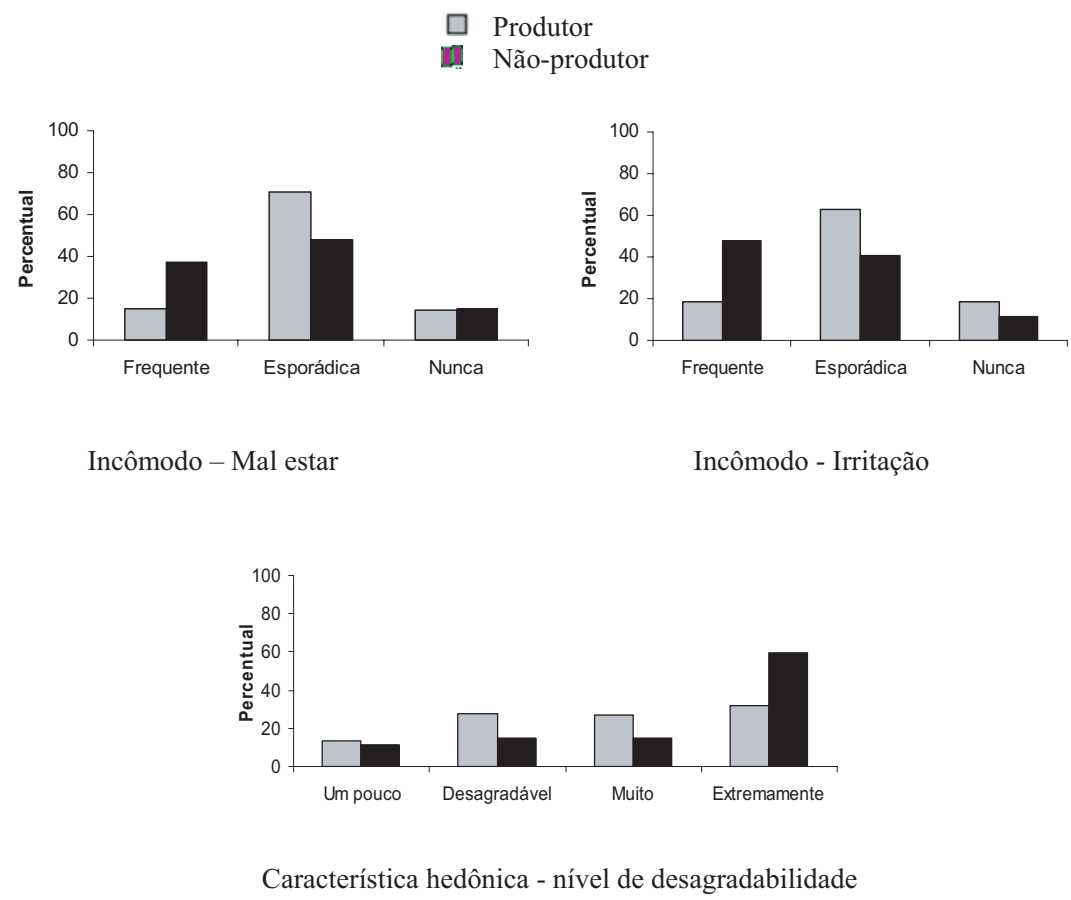

Figura 5 - Fatores de incômodos e características hedônicas dos odores

Tabela 3-Condições meteorológicas registradas durante as amostragens

\begin{tabular}{|c|c|c|c|c|c|c|}
\hline Ponto & Data/hora & $\begin{array}{l}\text { Condição do } \\
\text { tempo }\end{array}$ & $\begin{array}{l}\text { Temperatura } \\
\left({ }^{\circ} \mathrm{C}\right)\end{array}$ & $\begin{array}{l}\text { Umidade do ar } \\
(\%)\end{array}$ & $\begin{array}{c}\text { Direção } \\
\text { predominante } \\
\text { do vento }\end{array}$ & $\begin{array}{c}\text { Velocidade } \\
\text { média do vento } \\
(\mathrm{m} / \mathrm{s})\end{array}$ \\
\hline 1-Jusante da propriedade & $\begin{array}{l}\text { 04/nov } \\
13: 25 \text { hs }\end{array}$ & Nublado & 32,5 & 68,0 & $\mathrm{SE} \rightarrow \mathrm{NW}$ & 0,44 \\
\hline 2-Campo de Futebol & $\begin{array}{l}\text { 04/nov } \\
10: 40 \text { hs }\end{array}$ & Sol c/ nuvens & 29,0 & 75,0 & $\mathrm{SE} \rightarrow \mathrm{NW}$ & 2,26 \\
\hline $\begin{array}{l}\text { 3- Montante da } \\
\text { propriedade }\end{array}$ & $\begin{array}{l}\text { 04/nov } \\
14: 30 \text { hs }\end{array}$ & Sol c/ nuvens & 32,3 & 57,0 & $\mathrm{SE} \rightarrow \mathrm{NW}$ & 1,72 \\
\hline $\begin{array}{l}4 \text {-Interior da granja com } \\
\text { suínos }\end{array}$ & $\begin{array}{l}\text { 14/out } \\
13: 05 \text { hs }\end{array}$ & Nublado & 22,5 & 77,5 & - & - \\
\hline 5-Tanque Pulmão & $\begin{array}{l}\text { 14/out } \\
14: 55 \mathrm{hs}\end{array}$ & Nublado & 24,5 & 66,5 & $\mathrm{NE} \rightarrow \mathrm{SW}$ & 1,29 \\
\hline $\begin{array}{l}\text { 6-Residência do } \\
\text { produtor }\end{array}$ & $\begin{array}{l}\text { 14/out } \\
11: 20 \text { hs }\end{array}$ & Nublado & 21,0 & 85,0 & $\mathrm{NE} \rightarrow \mathrm{SW}$ & 0,31 \\
\hline
\end{tabular}


Tabela 4 - Resultados obtidos das análises com olfatômetro de diluição dinâmica

\begin{tabular}{cccc}
\hline $\begin{array}{c}\text { Pontos de } \\
\text { amostragens }\end{array}$ & $\begin{array}{c}\text { Local de } \\
\text { amostragens }\end{array}$ & \multicolumn{2}{c}{ Concentração odorante $\left(\mathrm{UO} / \mathrm{m}^{3}\right)$} \\
ASTM E679-91 & pr En 13725 \\
\hline 1 & $\begin{array}{c}\text { Jusante da } \\
\text { propriedade } \\
\text { Campo de futebol }\end{array}$ & 626 & 428 \\
3 & $\begin{array}{c}\text { Montante da } \\
\text { propriedade }\end{array}$ & 288 & 963 \\
4 & $\begin{array}{c}\text { Interior da granja } \\
\text { com suínos } \\
\text { Tanque pulmão }\end{array}$ & 378 & 290 \\
5 & Residência do & 716 & 576 \\
6 & produtor & 257 & 716 \\
\hline
\end{tabular}

*sem resultado

Os odores no campo de futebol e sobre a superfície do tanque pulmão foram aqueles que apresentaram maiores concentraçôes, tendo valores respectivos de $665 \mathrm{UO} / \mathrm{m}^{3}$ (ASTM) e $963 \mathrm{UO} / \mathrm{m}^{3}(\mathrm{prEN})$ para o primeiro local e $716 \mathrm{UO} / \mathrm{m}^{3}$ para o segundo local. O tanque pulmão realiza o armazenamento dos dejetos produzidos na propriedade. No caso do campo de futebol as elevadas concentraçôes se explicam porque a sua amostragem foi realizada no dia seguinte à aplicação de dejetos sobre o solo em áreas próximas.

De acordo com as condições atmosféricas na data da coleta na microbacia, acredita-se que a elevada temperatura, com tempo bom e tendo sol há mais de três dias propiciaram a persistência dos odores na região. $\mathrm{Na}$ visita à propriedade realizada na data da coleta das amostras dos pontos 1, 2 e 3 o odor percebido, pela equipe técnica na propriedade foi extremamente forte.

Os pontos com menores concentrações dos odores foram os de número 3 e 6 , sendo respectivamente à montante da propriedade e na residência do produtor. Entretanto, os valores refletem o grau de desconforto percebido pelas pessoas no momento das amostragens, haja vista que elas estavam recém chegadas de um local mais ameno. $\mathrm{O}$ ponto 3 , a montante, foi considerado o de menor concentração na microbacia, podendo ser resultado do relevo da região, mais plano e alto, facilitando a dispersão dos odores. Os valores das concentrações são da mesma ordem de grandeza estando com $288 \mathrm{UO} / \mathrm{m}^{3}$ (ASTM) e $290 \mathrm{UO} / \mathrm{m}^{3}$
(prEN) e apesar de serem relativamente inferiores, eles também proporcionaram incômodos olfativos.

No interior da granja com suínos na fase de engorda, foram obtidas concentraçōes de $378 \mathrm{UO} / \mathrm{m}^{3}$ (ASTM) e $576 \mathrm{UO} / \mathrm{m}^{3}$ ( $\mathrm{prEN}$ ). Todas as situações apresentaram concentrações elevadas.

Belli Fo (1995) avaliou as potencialidades de emissóes de odores de diferentes dejetos quando aplicados no solo e o principal responsável pelos maus odores de dejetos de suínos foi o $\mathrm{H}_{2}$ S. Seu trabalho comparou os odores de dejetos não tratados com dejetos tratados para eliminar este composto, que foi retirado com processo de extração de gás sulfídrico. Quando aplicados no solo, foi observado que a 50 metros no os dejetos não tratados foi obtida concentração de odor de $950 \mathrm{UO} / \mathrm{m}^{3}$. Para os dejetos tratados foi obtida concentração de $210 \mathrm{UO} / \mathrm{m}^{3}$. Apesar da significativa redução do odor sem a presença do gás sulfídrico, a existência de concentração odorante remanescente foi devido à persistência de amônia no ar proveniente deste resíduo. A concentração de $210 \mathrm{UO} / \mathrm{m}^{3}$ ainda fornecia intensidade odorante média e facilmente perceptível por um júri de pessoas.

Em relação a dispersão dos odores em região com forte densidade de suínos, Sheridan et al (2004) apresentam em seu trabalho que moradores próximos às unidades de produção de suínos sentiram-se incomodados com concentração de $4,3 \mathrm{UO} / \mathrm{m}^{3}$, apesar de a legislação irlandesa fixar o limite de $6 \mathrm{UO} / \mathrm{m}^{3}$. Esta distinção de valores mostra que se deve avançar em estudos momento dos seus lançamentos, para com a olfatometria para consolidá-la como instrumento de gestão dos odores.

\section{CONCLUSÕES}

Os estudos que foram conduzidos neste trabalho destacaram a importância da gestão dos odores para a suinocultura No Brasil.

A bacia hidrográfica do Rio Fragosos apresentou forte emissão de odores proveniente da suinocultura, percebida pelos produtores e não produtores de suínos, indicando que o seu ambiente apresenta riscos às saúdes. As percepções olfativas dos entrevistados indicaram características hedônicas de desagradabilidades no ambiente em que vivem, quando se utiliza o odor como parâmetro de referência para esta avaliação.

As concentrações de odores obtidas das amostras coletadas na microbacia hidrográfica do Rio Cachoeirinhas, apresentaram valores superiores aos permitidos por legislações de países que possuem uma normatização específica para este parâmetro de controle ambiental. A concentração de odor mínima encontrada foi na residência do produtor, com valor de $257 \mathrm{UO} / \mathrm{m}^{3}$ e apesar de possuir o menor entre os obtidos nesse trabalho, ainda proporcionava incômodo olfativo.

Nesse trabalho foi verificado que as variáveis atmosféricas influenciaram nas condições ambientais, proporcionando reflexos nas características dos odores e conseqüentemente aumentando ou diminuindo os incômodos populacionais.

Os resultados mostraram que as duas metodologias aplicadas para avaliações olfatométricas para a suinocultura fornecem condições de determinar o grau de conforto ambiental, em relação aos incômodos olfativos em uma bacia hidrográfica com esta atividade. É recomendável o uso das metodologias aqui propostas para avaliaçóes dos odores nesta atividade.

\section{REFERÊNCIAS}

ADEME/AFITE. Pollution olfactives des installations classées: De l'évaluation de la gêne aux techniques de réduction. Recuile des interventions. Journées techniques nationales. 301p. Paris. 2005.

ASTM-AMERICAN SOCIETY FOR TESTING AND MATERIALS. E 679-91 - Determination of Odor and Taste Tresholds by a Forced-Choice Ascending Series Method of Limits. American National Standard. 30 p. 1997. 
BELLI FILHO, P. Stockage et odeur de dejections animales- cas du lisier de porc. Tese doutorado Université de Rennes. 199 p. 1995.

BELLI FILHO, P.; LISBOA, M. H. Avaliação de Emissöes Odorantes. Engenharia Sanitária e Ambiental, Rio de Janeiro, V. 3, n. 3/4, jul/ set e out/dez., p.101-106. 1998.

CARMO JR.; G. N. R . Otimização e Aplicação de Metodologias para Análises Olfatométricas Integradas ao Saneamento Ambiental. Tese de Doutorado. Universidade Federal de Santa Catarina. 174 p. 2005.

CEN- PREN - EUROPEAN COMMITTE FOR STANDARDIZATION AIR QUALITY - Determination of Odour Concentration by Dinamic Olfatometry. 2003.

CGIR. Concentrations and emissions from farm building. Animal Housing. Commission Internationale du Génie Rural. France. P. 55-65. 1994

DE MELO LISBOA, H. Contribution a la Mise en Oeuvre et a la Validation de Modeles de Dispersion Atmospherique Applicables aux Composes. Tese de doutorado. Université Pau e Ecole Nationale Superieure dês Techniques Industrielles et de Mines d'Ales. 196 p. 1996

FATMA. Fundação do Meio Ambiente. Legislação Ambiental Básica do Estado de Santa Catarina. 1982.

GALLMANN, E.; HARTUNG, E. \& JUNGBLUTH, T. Field grid measurements to assess the odour impact in the vicinity of livestock farms. Environmental odour management Conference International, Cologne. VDI 309-318. 2004
JONCAS, R.; GODBOUT, S.; POULIOT, F. Un pied de nez aux odeurs provenant des bâtiments. Fédération des Producteurs de Porcs du Québec. Porc Quebec. 10 p. 2003.

PERRIN, M. L. et al. Étude de la gêne olfactive des populations riveraines des zones industrielles de l'estuaire de la seine. Pollution Atmosphérique. p. 66-73. Jan/mar. 1994.

ROUIL, L. Modelisation de la dispersion des odeurs. Pollution olfactives des installations classées: de l'évaluation de la gêne aux techniques de réduction. Recuile des interventions. Journées techniques nationales. 95 -104. Paris. 2005.

SHERIDAN, B. A.; et al. A dispersion modelling approach to determining the odour impact of intensive units in Ireland. Bioresource technology v. 91, p. $145-152.2004$

SILVA, G. P. Avaliação de Incômodos Olfativos emitidos pela Suinocultura - Estudos na Bacia Hidrográfica do Rio Fragosos e na Regiāo de Concórdia. Dissertação de Mestrado em Engenharia Ambiental. Universidade Federal de Santa Catarina. Florianópolis, 108 p. 2002

STUETZ, R. \& FRECHEN, F. B. Odours Wastewater Treatment. Measurement, Modelling and Control. IWA. 437 p. 2001.

VDI 3883 part 2. Effects and assessment of odours - Determination of Annoyance Parameters by Questioning - Reapted Brief Questioning of Neighbour Panellist. VDI -Verein Deutscher Ingenieure. 1993

VDI/DIN. European Conference on Odour Management. Cologne. 2004.
Endereço para correspondência:

Paulo Belli Filho

Departamento de Engenharia

Sanitária e Ambiental

Universidade Federal de Santa

Catarina

88040-900 Florianópolis - SC -

Brazil

Email: belli@ens.ufsc.br 